\title{
Fumigaciones, incumplimientos, coaliciones y resistencias
}

\author{
Fumigations, Breaches, Coalitions and Resistance \\ Fumigações, incumprimentos, coalisões e resistências
}

\section{FRANCISCO GUTIÉRREZ SANÍN*}

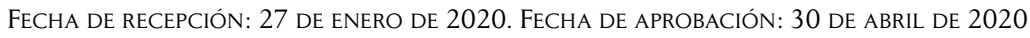

Doi: https://doi.org/10.12804/revistas.urosario.edu.co/sociojuridicos/a.9146

Para citar: Gutiérrez Sanín, F. (2020). Fumigaciones, incumplimientos, coaliciones y resistencias. Estudios Sociojurídicos, 22(2), 471-507. https://doi.org/10.12804/revistas.urosario.edu.co/sociojuridicos/a.9146

\section{RESUMEN}

Este artículo intenta explicar la forma en que el estado colombiano procesa las demandas y movilizaciones cocaleras: sentarse a negociar para después incumplir ("el ciclo de incumplimiento"). Muestro que, a pesar de lo aparentemente contraproducente que es, el ciclo es una forma persistente, quizás la principal, de respuesta de nuestro estado frente a las movilizaciones. Argumento que al menos parte del ciclo del incumplimiento se debe a la naturaleza de las coaliciones que soportan la guerra contra las drogas en Colombia. Por una parte, esas coaliciones son típicamente "largas", yendo desde lo global hasta lo puramente local, por lo que pueden cargarles costos prohibitivos a los campesinos cultivadores sin que los diseñadores de las políticas se vean afectados. Por la otra, esas coaliciones no siempre se han articulado fácilmente a la otra gran guerra global que se ha llevado a cabo en el país, la guerra contra la subversión. Ambas circunstancias generan permanentes bloqueos, inestabilidades y problemas de acción colectiva.

Palabras clave: movilizaciones cocaleras, coaliciones, estado, incumplimientos, abandono

* Los resultados presentados aquí son producto del proyecto "Drug and Disorder": https://drugs-and-disorder.org/. Aunque todo el equipo de investigación ha contribuido a ellos, agradezco aquí particularmente a Luis Castillo y Sebastián Cristancho.

** Profesor del Instituto de Estudios Políticos y Relaciones Internacionales de la Universidad Nacional de Colombia. Correo electrónico: gutiers2002@yahoo.com 


\section{ABSTRACT}

This article aims to explain how the Colombian state addresses coca demands and mobilizations: negotiating and then defaulting --the noncompliance cycle. Despite how apparently counterproductive it is, the cycle is persistent and, perhaps the main form of the state's response to those mobilizations. I argue that part of the noncompliance cycle is due to the nature of the coalitions that support the drug war in Colombia. Furthermore, these coalitions, typically long, range from global to purely local, so they can charge peasants with prohibitive costs without being affected by the new policies. In addition, these have not always been smoothly articulated to the country's greater waged global war, the war against subversion. Both circumstances generate permanent blockages, instabilities, and problems of collective action.

Keywords: Coca mobilizations, coalitions, state, breaches, abandonment.

\section{RESUMO}

Este artigo tenta explicar a forma em que o estado colombiano processa as demandas e mobilizações cocaleiras: sentar-se a negociar para depois descumprir ("o ciclo de incumprimento"). Mostro que, apesar do aparentemente contraproducente que é, o ciclo é uma forma persistente, talvez a principal, de resposta de nosso estado frente às mobilizações. Argumento que pelo menos parte do ciclo do incumprimento se deve à natureza das coalisões que suportam a guerra contra as drogas na Colômbia. Por uma parte, essas coalisões são tipicamente "longas", indo desde o global até o puramente local, pelo que podem carregar-lhes custos proibitivos aos camponeses cultivadores sem que os desenhadores das políticas se vejam afetados. Pelo outro lado, essas coalisões não sempre se têm articulado facilmente à outra guerra global que se tem levado a cabo no país, a guerra contra a subversão. Ambas as circunstâncias geram permanentes bloqueios, instabilidades e problemas de ação coletiva.

Palavras-chave: mobilizações cocaleiras, coalisões, estado, incumprimentos, abandono. 


\section{Introducción: el rompecabezas y la pregunta}

En este artículo, plantearé que la respuesta básica del Estado a las movilizaciones cocaleras consiste en lo que llamaré el 'ciclo del incumplimiento'. A la vez, propondré una explicación de por qué se produce: por las dificultades persistentes por parte del Estado colombiano para construir coaliciones estables alrededor de sus políticas frente a los cultivos ilícitos. Tales políticas no son autosostenibles, pues generan sistemas de incentivos y problemas de acción colectiva que se expresan a través de permanentes desalineamientos de actores claves a todos los niveles territoriales.

El ciclo del incumplimiento consiste de dos movimientos. Primero, el Estado se muestra dispuesto a negociar y a llegar a acuerdos frente a las protestas. De hecho, buena parte de ellos se formalizan por medio de actas y eventos solemnes. Segundo, el Estado no cumple con lo establecido en esas actas y eventos. El problema analítico, pero también de política pública, que plantea el ciclo es que las explicaciones y visiones más comunes sobre el Estado y su desempeño solamente pueden explicar uno de los dos componentes del mecanismo; más aún, los criterios que ofrecen para entender uno de los componentes del ciclo impiden comprender la existencia del otro.

El ciclo también genera una perplejidad, que no es fácil de responder. ¿Por qué diablos sentarse a negociar para después incumplir? ¿Cuál es el propósito? ¿Lo hay? Son preguntas más bien evidentes, pero no tan fáciles de contestar. La extrañeza se hace mayor cuando se tiene en cuenta la enorme centralidad que ha tenido la política antidrogas -en general, y contra los cultivos ilícitos en particular- en el país en los últimos años. En efecto, diversas figuras gubernamentales han afirmado obsesivamente que en los territorios cocaleros se están jugando apuestas fundamentales para la seguridad del Estado colombiano. De hecho, la idea de que el narcotráfico era la gasolina de la guerra se convirtió en explicación oficial del conflicto desde mediados de la década de 1980; también aparece, así sea en sordina, en el Acuerdo Final entre el gobierno y las FARC. Eso convirtió a la lucha contra los cultivos ilícitos en una de las prioridades de la guerra contrainsurgente. La retórica estatal -incluyendo no solamente la 'producida para la galería', sino aquella 
orientada más bien a auditorios tecnocráticos para respaldar la toma de decisiones - recogió exactamente los mismos motivos: la lucha contra las drogas era LA prioridad de las políticas de seguridad nacional. Además, parece haber un claro correlato entre esa retórica estatal y la creciente articulación entre distintas guerrillas con diferentes economías ilícitas desde la década de 1980. Es decir, el Estado colombiano parecería tener precisamente los incentivos a partir de los cuales la teoría belicista del Estado predice un gradual escalamiento de sus capacidades (Castaneda E Schneider, 2017): una amenaza existencial, vinculada al alcance territorial del Estado, cuya solución pasa por la movilización de grandes medios de violencia.

Además, si la sustitución voluntaria puede producir efectos positivos, ¿por qué no insistir en esa vía, que podría permitir a los sucesivos gobiernos apaciguar tanto a Estados Unidos - disminuyendo áreas cultivadas - como a los campesinos - atendiendo a sus reivindicaciones-? ${ }^{1}$ Por último, la demanda histórica de los campesinos, no por casualidad, ha sido la lucha contra el "abandono" (Karl, 2017): exigiendo presencia del Estado, en diversas formas. ¿Por qué no responder a estas exigencias para ampliar el alcance territorial de un Estado que necesita desesperadamente hacerlo?

Nótese que aquí estamos hablando del corazón de cualquier noción contemporánea de Estado: su alcance territorial. Las demandas de las protestas cocaleras se han centrado en la argumentación de que sin dotación de bienes públicos el campesinado no tiene alternativas viables a la coca. Por consiguiente, uno de los puntos focales de sus pliegos, y de los correspondientes acuerdos con el Estado, ha sido la superación del abandono.

Argumentaré aquí que los dos momentos del ciclo del incumplimiento se pueden explicar plenamente si se ponen en el centro del análisis a las coaliciones que rodean y desarrollan las políticas y respuestas estatales, así como los problemas que dimanan de su alineamiento. Para todos

1 Por ejemplo, Bolivia a cargo de Evo Morales impulsó una política que mantuvo el área cultivada bajo control sin perder su apoyo social dentro del campesinado cocalero. El contexto es muy distinto claro, pero el punto es que esas políticas ya se han imaginado, planteado e implementado (de hecho, con bastante éxito) al mismo nivel de desarrollo. 
los Estados y todas las políticas, en general, es un hecho que estas se vuelven insostenibles cuando actores centrales les quitan el apoyo. Para Estados como el colombiano y para políticas como las de lucha contra los cultivos ilícitos, esto es cierto en grado mayúsculo por al menos tres factores. Primero, el Estado colombiano en buena parte está construido sobre el "dominio indirecto" (Mann, 1993): el Estado central extiende y mantiene su alcance territorial a través de una panoplia de élites, notables e intermediarios regionales. Segundo, la política contra los cultivos ilícitos es transnacional, y está vinculada a las dos grandes guerras globales que se libran en Colombia. Estos dos factores juntos llevan al tercero: tal política requiere entonces de 'coaliciones largas', que mantengan apoyos a todos los niveles territoriales involucrados en su desarrollo. Eso implica que tienen que mantener coaliciones tanto en Washington como en el nivel departamental (y a veces en el municipio y la vereda). ¿Es posible alinear adecuadamente tales coaliciones a los diferentes niveles territoriales en los que se decide e implementa la política? Mostraré aquí que esa tarea ha resultado excesivamente complicada para el Estado. Por la naturaleza de la política contra los cultivos ilícitos el Estado no ha podido construir esas coaliciones largas que se reproduzcan a sí mismas (es decir, sostenibles) -lo que se expresa a través de múltiples problemas de acción colectiva a los que se refiere la proposición explicativa que planteo aquí-. Más aún, la comprensión del ciclo desde la perspectiva de las coaliciones puede ayudar a explicar fenómenos de debilidad burocrática que de manera ostensible subyacen a las respuestas estatales a demandas desde regiones productoras de cultivos de uso ilícito.

Por supuesto que se podría argumentar que el ciclo del incumplimiento no se observa exclusivamente en la respuesta estatal a las movilizaciones cocaleras. En efecto, una parte significativa de las protestas ciudadanas que se producen en Colombia tiene entre sus principales motivaciones exigir el cumplimiento de acuerdos pasados que habían cerrado ciclos de movilización previos. Aunque aún falta producir mucha más evidencia sistemática al respecto, sabemos que frecuentemente la gente se moviliza en el país porque en parte le incumplieron compromisos previos. El incumplimiento, por ejemplo, fue una motivación central de la vigorosa oleada de protestas que sacudieron al país en 2019 y que 
tuvieron como escenario las grandes ciudades (Semana, 2019). Lo mismo se puede decir del mundo rural. Uno de los motivos centrales detrás de la minga indígena y campesina de marzo de 2019 fue el incumplimiento masivo de acuerdos previos por parte del Estado (Uniandes, 2019). El gobierno de Iván Duque se comprometió a resolver el problema adoptando una posición fiscalmente responsable, superando la lógica de las promesas vacías del pasado, pero pronto tuvo que lidiar con críticas a sus propios incumplimientos (RCN Radio, 2019). Si, en lugar de concentrarnos en escenarios territoriales, dirigimos nuestra atención a los sectores productivos, nos encontramos con idéntico panorama. Por ejemplo, casi desde el principio los pliegos y demandas relacionados con la economía petrolera en el Putumayo han dado una gran centralidad al incumplimiento de los compromisos por parte del gobierno y la empresa -ver, por ejemplo, AGN (1974)-. Encontramos tematizaciones análogas en otros territorios con presencia de empresas petroleras.

Con todo y esto, probablemente el sector social más afectado por los incumplimientos sea el campesinado cocalero. Aunque algunas de las demandas del campesinado cocalero sí parecen haberse traducido en ejecuciones reales -como sucedió con las del Catatumbo en 2013 (entrevista; CNMH, 2018)-, en muchos casos los acuerdos se han quedado mayoritaria o totalmente en el papel o se han dejado marchitar. Este parecería ser el destino del PNIS, la política pública nacida del acuerdo de paz entre el gobierno y las FARC, que preveía una sustitución de cultivos ilícitos con amplia dotación de bienes públicos y anclada en la participación comunitaria. Puntos cruciales de casi todos los pactos entre Estado y cocaleros - dotación de bienes públicos y sustitución voluntaria, así como tratamiento penal diferenciado- han sido acordados en diferentes modalidades, pero el resultado ulterior ha sido en general el inverso al esperado por los campesinos. Este desenlace notable se encuentra ya reportado en el primer producto académico que tenemos sobre la materia, uno de cuyos objetivos centrales era estudiar un pacto local de sustitución en el contexto del proceso de paz entre el gobierno y las FARC en la década de 1980, que fue groseramente incumplido por el gobierno más o menos desde el principio (Jaramillo, et al., 1989).

Ahora bien: que el campesinado cocalero sea el eslabón más débil de una lógica de incumplimiento gubernamental a duras penas puede 
considerarse sorpresivo, en vista de su vulnerabilidad -al ser en palabras de William Ramírez (1996), "un campesinado ilícito" y el blanco de una política prohibicionista establecida por Estados Unidos en un país en el que la potencia del norte tiene un peso enorme-. Que esa lógica, empero, se aplique a las políticas de erradicación o sustitución de los cultivos ilícitos ya demanda una explicación. En efecto, por todas las razones aducidas antes, incumplir parecería ser una típica solución 'pierde-pierde', o desde otra perspectiva una forma espectacular de miopía estatal: solucionar un problema hoy para enfrentar otro más grande mañana.

El artículo procede de la siguiente manera. En la primera parte, reviso algunos de los conceptos centrales usados aquí a la luz de la literatura relevante. La segunda sección está dedicada a mostrar que en efecto las demandas sociales en los territorios cocaleros han sido generalmente respondidas con el ciclo de incumplimiento. No evalúo la trayectoria de todas las movilizaciones cocaleras, pero sí algunas de las más emblemáticas. El tercer apartado se concentra en la explicación del ciclo del incumplimiento, y muestra en qué consiste la desalineación de coaliciones y cómo se relaciona con diferentes formas de debilidad burocrática. Las conclusiones llevan a cabo tres operaciones. Primero, recapitulan. Segundo, plantean que la explicación desarrollada aquí es consistente incluso después de tener en cuenta algunos contraargumentos significativos. Tercero, exponen algunas preguntas metodológicas y comparativas.

Con respecto de los datos utilizados aquí, me apoyo principalmente en material de archivo, pero también en entrevistas en profundidad y fuentes de prensa.

\section{El incumplimiento y el Estado colombiano}

¿Cómo responde el Estado colombiano a las demandas sociales, particularmente a las del campesinado y a las de las regiones geográficamente más apartadas del centro andino del país? De lejos, el grueso de respuestas a esta pregunta en la literatura relevante parece concentrarse en dos palabras: 'exclusión' y 'abandono'. 
Si adjudicáramos un poco mecánicamente la expresión 'abandono' a relaciones territoriales y 'exclusión' a relaciones sociales, tendríamos rápidamente elementos para dar un panorama completo. Sabemos que la prestación de servicios y bienes públicos por parte del Estado en las regiones que rodean el núcleo andino del país es tremendamente deficiente, hasta el punto de que la situación ha sido bautizada por García y Espinosa (2014) con la feliz expresión de "apartheid institucional". Karl (2017) muestra cuánto peso ha tenido el abandono en las dinámicas pero también en las representaciones públicas de paz y guerra. Por otra parte, los campesinos colombianos no han sido solamente objeto de exclusión, sino blanco de violencias masiva en las últimas décadas.

Para el campesinado cocalero, el apartheid institucional y la exclusión sistemática van de la mano (Ramírez, 2005), pues es en los cultivos ilícitos donde encarna con particular claridad la relación íntima entre exclusión -como estigmatización y renuencia a tramitar incluso demandas elementales desde abajo (Ramírez, 2005; Torres, 2011) - y abandono: los campesinos cocaleros argumentan que para hacer el tránsito a economías legales necesitan dotación de bienes públicos, es decir, presencia del Estado en el territorio. Por consiguiente, sus demandas básicas (ver siguiente sección) se han dirigido contra la violencia estatal, la exclusión y el abandono, así como contra sus vínculos mutuos. Es decir, la literatura muestra con bastante claridad que el campesinado cocalero está en realidad impulsando dos objetivos íntimamente relacionados pero analíticamente diferenciables: la inclusión social y la inclusión territorial. Numerosos textos - comenzando por el clásico y posiblemente primer trabajo sistemático sobre la materia (Jaramillo, Mora \& Cubides, 1989) - no solo han hecho énfasis en esto, sino que han reproducido los pliegos de peticiones de quienes protestan o de quienes demandan alguna suerte de arreglo territorial que los incluya. Tales pliegos revelan la centralidad de las dos inclusiones.

Ahora bien, todo esto - que ha sido corroborado numerosas veces por toda clase de evidencia- aumenta la perplejidad con respecto de la existencia del ciclo de incumplimiento, pues, como señala en detalle Ramírez (2001), las demandas cocaleras exigen más, y no menos, Estado. Peor aún: aduce que el incumplimiento terminó convirtiéndose 
en un punto focal de numerosas exigencias y movilizaciones (algo que corroboro en la siguiente sección).

Entonces, ¿por qué no se ha corregido el ciclo de incumplimiento? Por fortuna o por desgracia, conceptualizaciones como las de 'debilidad del Estado' no están ya en boga y han caído bajo ataque. Lo mismo se puede decir con respecto de la noción de 'ausencia'. Por fortuna, por sus numerosos problemas e indeterminaciones (¿qué es debilidad?, ¿cómo se operacionaliza el concepto?). Por desgracia, porque las críticas a ese concepto parecen partir a menudo de un funcionalismo primitivo (el Estado en realidad no es débil porque obtiene en los territorios los resultados que deseaba). Sin embargo, si nos centramos en las dimensiones puramente logístico-administrativas del Estado, es decir, en el Estado como aparato organizacional (Skocpol, 2015; Mann, 1993), este sí que aparece débil en los territorios: eso es precisamente lo que muestra con contundencia la literatura sobre abandono y apartheid institucional. Además, las nociones de debilidad y ausencia parecen capturar una parte muy importante de la experiencia vivida por miles de personas en el territorio.

¿Cómo capturar esta experiencia sin sacrificar los aspectos rescatables de la crítica a los conceptos de debilidad o ausencia del Estado? La ruta que desarrollo aquí para enfrentar este problema es la siguiente. La debilidad o la ausencia se expresan y pueden ser observadas directamente en su dimensión administrativa, pero son resultado también de procesos y desenlaces políticos. Cuando se habla de 'ausencia del Estado' se denota una realidad operacional (presencia débil o nula de burocracias civiles, poca o ninguna dotación de bienes públicos, etc.), pero se corre el peligro de ignorar el proceso político que subyace a ella. En el caso concreto de las llamadas 'ausencia' o 'debilidad', podríamos decir que tal proceso está íntimamente relacionado con dos dimensiones. La primera es simplemente que Colombia ha estado en guerra todos estos años. En realidad, ha estado en medio de dos grandes guerras articuladas a fuerzas globales (Gutiérrez, 2019): la guerra contrainsurgente y la guerra contra las drogas. Aunque esta última es una guerra un poco en un sentido metafórico, no es por eso menos real: constituye una prioridad de 'seguridad nacional' estadounidense y una agenda expresada con 
urgencia y de manera arrolladora ante las autoridades colombianas. La confluencia de esas dos guerras es fundamental para entender el desempeño estatal, así como la forma en que han funcionado diferentes maneras de delegación de la seguridad del centro de toma de decisiones a los territorios (Gutiérrez, 2019).

Esto me lleva a la segunda dimensión: quien habla de guerra habla de territorio. En nuestro contexto, uno de los primeros en poner esa constatación en el centro del análisis fue Romero (2003), abriendo así una rica senda de indagación. Romero, recogiendo elementos de la teoría belicosa de la formación del Estado (Castaneda \& Schneider, 2017), planteó que los paramilitares habían sido promovidos por una alianza entre un ejército vinculado íntimamente a lógicas contrainsurgentes y élites territoriales opuestas a las iniciativas pacifistas del Estado central para mantener el statu quo regional. No obstante, los supuestos involucrados en la perspectiva de Tilly se han puesto en cuestión con un conjunto de evidencias e ideas de gran interés - ver, por ejemplo, Ciro (2014) y Ocampo (2015) -. ¿Son siempre tan positivas ${ }^{2}$ las iniciativas que dimanan del centro y tan negativas las de las élites regionales?

¿Cómo entonces pensar ausencia y debilidad desde la perspectiva de la guerra y el territorio? En este artículo recojo y desarrollo ideas sobre el particular planteadas en 2014 y 2019. Mi argumento básico es el siguiente: el problema no es preguntarse dónde está el locus del mal, si en el centro o en los territorios, es más bien preguntarse quiénes, cómo y para qué se relacionan a diferentes niveles territoriales. Todos los Estados tienen que alinear sus apoyos territoriales. Más en situaciones de guerra, más en Estados como el colombiano (González, 2014; Gutiérrez, 2019), en donde el alcance territorial del Estado se ha ido ensanchando - a menudo en medio de la guerra contrainsurgente- a través de una densa red de intermediarios, redes clientelistas, mandaderos y lleva-ytraes, que configuran la presencia del Estado realmente existente en

2 Obviamente, habría que preguntarse 'positivas con respecto de qué'. Tilly estaba adoptando en sus trabajos una perspectiva de formación de Estado y una mirada temporal muy larga, no necesariamente de ampliación de la esfera democrática o de los derechos. Como se recordará, en su obra hay una especie de 'confluencia milagrosa' entre fortalecimiento del Estado vía dinámicas militares y democratización. Pero que esa confluencia aparezca no es una necesidad lógica, fue un evento singular que podría o no repetirse. 
los territorios - ver al respecto el trabajo clásico de Blok (1974) sobre la mafia; ${ }^{3}$ ver también Mann y su concepto de dominio indirecto (1993)-. En este tipo de relación entre centro estatal y territorio, la probabilidad de que aparezcan problemas de acción colectiva, como los que identificó Romero (2003), entre diferentes élites nacionales y regionales es alta.

Sin embargo, aquí aún hay cabos sueltos importantes. Si el foco de atención es 'quiénes, cómo y para qué', entonces necesitamos de dos conceptos adicionales para dar cuenta de la complejidad adicional que estamos introduciendo al análisis. El primero es el de la inconsistencia y variación en el cómo y el para qué. En efecto, el Estado podría estar relacionándose de manera distinta con sus élites e intermediarios para diferentes políticas que está promoviendo; además, entre más indirecto sea el dominio, mayor variación regional observaremos en la apropiación y respuesta a esas políticas. Como veremos, este es precisamente el caso que se considera aquí. El tipo de alineamientos característico de la guerra contrainsurgente no se reproduce mecánicamente en el de la política contra los cultivos ilícitos (aunque obviamente desde Washington y desde Bogotá quisieran que fuera así). La inconsistencia y la variación acompañan permanentemente la implementación de las políticas.

El segundo es el de las coaliciones. De manera muy sorprendente para mí, las coaliciones han pasado bastante inadvertidas para la teoría política contemporánea. Retomando a Cook (2002), uno de los pocos autores que se centran seriamente en el concepto, definiré las coaliciones como formas de interacción humana que están en el 'corazón de la política' y que consisten en "la puesta en común colaborativa de recursos para obtener objetivos comunes y compatibles". De modo útil para toda la argumentación desarrollada acá, Cook afirma que las coaliciones habitualmente se articulan alrededor de objetivos relacionados con la coerción. ${ }^{4}$ Para toda política sostenible, es fundamental construir coaliciones que tengan 'objetivos compatibles y comunes' para todos los actores involucrados.

3 Aunque, para eliminar cualquier fuente potencial de confusión, esto NO quiere decir que esté insinuando que este mundo de intermediación constituya una mafia.

4 Incluyendo esto en la definición, cosa que definitivamente no hubiera debido hacer. 
Este sencillo aparato conceptual a su vez permite llevar a cabo dos operaciones. Por un lado, entender desenlaces logístico-administrativos ('debilidad', 'ausencia') que son resultado de interacciones entre coaliciones, es decir, articularlos a una comprensión observable y evaluable del proceso político. Por el otro, plantear de manera más precisa la proposición con la que pretendo responder a la pregunta por el ciclo de incumplimiento. Este se debe a que la política contra los cultivos ilícitos involucra coaliciones transnacionales largas (que a menudo van desde la vereda hasta Washington) que por la naturaleza de sus objetivos son inconsistentes (internamente, y con respecto de las coaliciones contrainsurgentes) -es decir, no sostenibles-. Los problemas que genera esto se reflejan en bruscas variaciones en la apropiación regional de las políticas y en problemas de acción colectiva básicamente intratables, lo que explica los incumplimientos continuos y también contribuye a la comprensión del abandono. Como corolario importante, la relación del centro con las élites regionales puede variar dependiendo del tipo de política y coalición.

\section{El ciclo del incumplimiento: la evidencia}

Después de lanzada en 2017 la política de sustitución de cultivos emanada del acuerdo de paz entre la por entonces principal guerrilla colombiana - las FARC- y el Estado, el programa correspondiente - el Programa Nacional Integral de Sustitución de Cultivos Ilícitos, o PNISpublicó un libro en el que tácitamente se aceptaba la larga trayectoria de incumplimientos estatales, y, por consiguiente, de desconfianzas, que tendría que superar. "Hemos dado esos primeros pasos fundamentales - decía el director del programa- con la garantía del gobierno en el sentido de que se cumple la palabra empeñada" (Díaz, Tulande \& Riveros, 2018 , p. 9). Un campesino entrevistado para la publicación afirmaba que "todo fue muy difícil al principio porque había desconfianza" (Díaz, Tulande E Riveros, 2018, p. 109). Bermúdez (2018, p. 193) sostiene que medidas claves contempladas en el PNIS - como el tratamiento penal diferencial- estaban dirigidas a restablecer "un grado mínimo de confianza". Distintos sondeos de opinión y estudios muestran, en efecto, 
que la desconfianza hacia el Estado colombiano está profundamente arraigada en diversos sectores.

El tono humilde del libro - "un abandono de toda la vida no se cura con un anuncio", reconocía (Díaz, Tulande \& Riveros, 2018, p. 64) - no era gratuito. El PNIS se implementaba sobre un trasfondo de enorme malestar entre el campesinado cocalero y más ampliamente numerosos actores regionales, causado, entre otros motivos, por una larga trayectoria de promesas incumplidas, acuerdos firmados y después no implementados, y apartheid institucional.

Por eso, algunas de las demandas de los campesinos cocaleros se han mantenido en el tiempo, coincidiendo además en buena parte con las que han levantado frente a otras economías. Estas demandas, de hecho, no han cristalizado en, por ejemplo, la búsqueda de distintas formas de legalización -algo que sí han hecho actores urbanos o concentrados en temas relativos al consumo-, sino más bien en una propuesta de pacto regional constituido por los siguientes elementos: la suspensión de las fumigaciones aéreas con glifosato, alguna forma de sustitución que sea voluntaria, la disminución de la represión, el incremento de la presencia de agencias civiles del Estado y, crucialmente, la provisión de bienes y servicios públicos -esto ya aparece esbozado desde el principio (ver Jaramillo, et al., 1989; Ramírez, 2001)-. Como lo han notado repetidamente las demandas campesinas, y como lo han aceptado sucesivos gobiernos, es poco creíble que pueda haber alguna forma de sustitución sostenible de cultivos sin la provisión de servicios públicos, incluida una asistencia técnica funcional, que permita la viabilidad de la economía campesina legal.

Tenemos el privilegio de contar con una descripción detallada de un primer acuerdo regional entre campesinos cocaleros y el gobierno en el marco de un proceso de paz, esta vez entre las FARC y el gobierno de Belisario Betancur, por parte además de un libro que se ha convertido en un clásico en la materia (Jaramillo, et al., 1989). Se llamaba Proyecto Caguán. Los autores consideraban que tanto los acuerdos de paz como el Proyecto Caguán "han creado las condiciones subjetivas y materiales para una reorientación de fondo de la estructura económica regional" (Jaramillo, et al., 1989, p. 153). Un campesino les decía en una entrevista: "Hoy en día, pues, todos los campesinos estamos decididos a acabar 
con la coca, siempre y cuando haya reivindicaciones para la región" (Jaramillo, et al., 1989, p. 154).

Pese a estas condiciones favorables, el proyecto nunca despegó. Para los autores, hay tres factores que explican este fracaso. Primero, tanto actores políticos como agencias estatales con gran peso nacional y regional se dedicaron a bombardear sistemáticamente la implementación. Es lo que hizo "el partido liberal oficialista" al "enfilar sus baterías contra el proyecto" (Jaramillo, et al., 1989, p. 116). En cuanto a las agencias estatales, no solamente la Brigada XII del Ejército, sino el consejero de paz - a la sazón Carlos Ossa Escobar-, hostilizaron y desautorizaron el proyecto en momentos críticos (Jaramillo, et al., 1989, pp. 214-217). Hay que notar, no obstante, que varias agencias, sobre todo las relacionadas con políticas agrarias, sí promovieron el Proyecto Caguán. Segundo, algunos niveles territoriales fundamentales nunca participaron en el esfuerzo. Particularmente, la Gobernación de Caquetá estuvo ausente (Jaramillo, et al., 1989, p. 210). Tercero, el proceso de paz, en el contexto del cual se había formulado el proyecto, hizo crisis a nivel nacional, bajo el impacto de actos brutales de distintas fuerzas - tanto gubernamentales como insurgentes-. Entre tanto, localmente, la organización social que sustentaba el Proyecto Caguán se había debilitado y dividido.

La década de 1990 estuvo marcada por enormes movilizaciones cocaleras. Aunque se produjeron en varias partes del país, uno de los puntos focales que tuvieron en común fue la oposición a la fumigación con glifosato. También el cumplimiento de acuerdos pasados estaba en el centro de las demandas. Criticar el incumplimiento implicaba que las movilizaciones de la década de 1990 conminaran al gobierno a aceptar su corresponsabilidad en el problema de los cultivos ilícitos. Por ejemplo, el paro cívico del Bajo Putumayo exigía "del gobierno central el reconocimiento de su parte que el abandono y la pobre inversión social también han contribuido en gran proporción a los problemas que ahora nos aquejan y es hora de un compromiso serio y efectivo" (Ríos, 1997, p. 29). El movimiento comenzó en diciembre de 1994 y se prolongó hasta enero de 1995. Como contamos con un buen relato (Ríos, 1997) sobre cómo se llevó a cabo parte del proceso de toma de decisiones durante el paro, sabemos que el gobierno entró en pánico frente a la movilización y que no tenía clara la respuesta que daría a ella. Envió a 
José Noé Ríos como negociador, apoyado en una magra delegación sin casi capacidades tecnocráticas o de decisión.

Ríos (1997) destaca su tremendo aislamiento y las dificultades que tuvo para coordinar las posiciones a menudo encontradas de la Presidencia, el Ministerio del Interior, el Ministerio de Defensa y la Consejería de Paz, para no hablar de las suyas propias. Destaca también en su relato el vacío burocrático e institucional en el que se movió. Tanto la prensa de la época como información adicional por parte de analistas del evento (entrevistas 1 y 2 ) nos muestran que también se enfrentó a otro problema de gran magnitud: los acuerdos a los que finalmente llegó después de una dura negociación con los campesinos fueron inmediatamente sometidos a fuego por parte de agentes dentro del gobierno, que creían que la sustitución progresiva iba contra las leyes colombianas y -sotto voce- que eran inaceptables 'para los gringos'.

Por eso, la inauguración misma de los acuerdos comenzó con un incumplimiento: se había incluido en ellos la palabra "progresiva" para referirse a la sustitución, y la delegación gubernamental la sacó a través de marrullas de la redacción final (El Tiempo, 1995; entrevista 3). El gobierno pronto mostró que tampoco cumpliría con otras demandas vitales que provenían del territorio y que había acordado formalmente con los campesinos. Por ejemplo, el Acuerdo de San José del 15 de diciembre de 1994 estipulaba que los campesinos adelantarían una "sustitución gradual" y "por su parte el gobierno se compromete a suspender la fumigación de los pequeños cultivos de coca existentes a la fecha del presente acuerdo, entendiéndose como tales, aquellos inferiores a tres hectáreas de extensión" (Acta del Acuerdo de San José, 15 de diciembre de 1994). Pero después tanto personas dentro del gobierno como distintas agencias (por ejemplo, ${ }^{5}$ la Fiscalía) consideraron que la suspensión de la fumigación y el principio de gradualidad resultaban inaceptables.

Mientras tanto, el coro de voces contra la fumigación iba creciendo. Por ejemplo, a nivel regional la Iglesia católica se manifestó en contra de ella. La Asamblea Pastoral de Villagarzón advirtió que las fumigaciones eran una "forma brutal y salvaje" de proceder que "atenta[ba] contra la vida", y que "generaría más violencia" (DAPRE, 1995a); y tanto

5 Para detalles sobre la negociación, ver El Tiempo (1994). 
gobernadores como alcaldes manifestaron su preocupación por lo que estaba sucediendo.

Los gobernantes del sur del país no fueron los únicos, de hecho ni siquiera los primeros, en expresar su insatisfacción con las fumigaciones. En 1993, el exgobernador Trino Luna Morón, secundado por políticos regionales con peso nacional, había ya puesto sobre la mesa una proposición en la asamblea departamental del Magdalena -en el norte del país - contra "el uso indiscriminado del glifosato" para eliminar los cultivos ilícitos en la región. La proposición fue aprobada por amplia mayoría, y copia de ella fue enviada al presidente de la república, César Gaviria, y al gobernador del departamento, Miguel Pinedo Vidal. Pero Pinedo había manifestado ya su "oposición rotunda" a las fumigaciones con glifosato (El Informador, 1992). En esto los políticos tenían el respaldo pleno del empresariado regional. En 1993, por ejemplo, los gremios de la producción del departamento del Magdalena manifestaron en "público su rechazo al uso indiscriminado del glifosato para destruir plantaciones de marihuana, hoja de coca y amapola en el país". Llegaron incluso a amenazar al gobierno con promover un paro cívico si esas fumigaciones tenían lugar (El Informador, 1993).

La situación era un polvorín. Mientras tanto, en el sur -como lo había predicho ya a la administración Samper la Gobernación del Guaviare (DAPRE, 1995b) - la indignación generalizada estaba creando las condiciones para otra movilización cocalera. Esta tuvo lugar en 1996 y fue de enormes proporciones, extendiéndose a varios departamentos. En el Putumayo fue coordinada por el Movimiento Cívico, que incluía de manera orgánica a los alcaldes del departamento (Ramírez, 2001). En algún punto se sumaron a la movilización distintos actores sociales, incluidos los indígenas, que también reclamaban por los incumplimientos de los que habían sido víctimas (El Espectador, 1996a). Los pliegos se parecían mucho a los del ciclo inmediatamente anterior. Se dirigían contra las fumigaciones, y de paso contra el programa de erradicación/ sustitución del presidente del período, Ernesto Samper (llamado Plante) (El Espectador, 1996a). Las demandas también incluían provisión de bienes públicos y aspectos claves para el desarrollo regional -el pliego completo se encuentra en Ramírez (2001, pp. 218-223)-, pero también estaban 
motivadas explícitamente por los incumplimientos de los acuerdos de 1995 (El Espectador, 1996a).

El Ejército fue enviado contra los exasperados campesinos, lo que degeneró en enfrentamientos campales (El Espectador, 1996b). La retórica pública del Ejército era que el movimiento constituía una maniobra de la subversión (El Espectador, 1996a), lo que permitía reprimirlo sin contemplaciones. En el contexto de una guerra civil en pleno desenvolvimiento, los campesinos quedaron atrapados, como reza el título del libro de Ramírez, "entre el Estado y la guerrilla".

Aun así, finalmente se llegó a un acuerdo. Distintas voces pidieron la supervisión de su implementación por parte de terceros creíbles, como la Iglesia. Pero, inmediatamente después de la firma del acuerdo, comenzaron los incumplimientos (La Nación, 1996). Eso llevó al gobernador del Putumayo a amenazar con "un paro administrativo" en el departamento si no se llevaba a cabo "lo acordado con el territorio" (La Nación, 1996). La amenaza iba en serio, según un documento interno del gobierno (DAPRE, 1995b).

De ahí en adelante, se han producido numerosas movilizaciones regionales, algunas de gran impacto (como la protesta de los campesinos cocaleros en Tibú en 2013). Muchas de ellas han logrado llevar al gobierno a una mesa de negociación. En algunos casos, los gobiernos han iniciado negociaciones profilácticas para prevenir la movilización, lo que ha llevado a la firma de reiterados acuerdos (La Silla Vacía, 2017). Aunque no es razonable decir que todos estos compromisos se incumplieron -algunos sí, otros no, otros parcialmente-, sí es justo afirmar que todos ellos estuvieron marcados por el espectro del incumplimiento. Aun en 2014 el acuerdo firmado entre organizaciones sociales del Putumayo y el gobierno -representado por varios ministros, incluido el del Interior, lo que revela la fuerza del movimiento- incluía entre los compromisos del gobierno "revisar y cumplir los acuerdos firmados por el gobierno nacional desde el año 1996 hasta la fecha" (Acta de Acuerdos entre la Mesa Regional de Organizaciones Sociales del Putumayo, Alta Bota Caucana y Jardines de Sucumbíos de Ipiales y el Gobierno Nacional, 2014).

Esto ya estaba teniendo lugar mientras el gobierno y las FARC negociaban en La Habana. De allí salió el PNIS, que se suponía lograría 
superar esta larga trayectoria de violación de los compromisos. Además, en este caso el cubrimiento fue muy grande -con el número de inscritos pasando de cien mil-y las familias cocaleras pudieron conformarse en un conjunto de organizaciones legales (la más grande de las cuales es Coccam) que tenían una clara interfaz con el Estado para tramitar sus demandas. Aún más, en 2015 se suspendieron las fumigaciones aéreas con glifosato, debido tanto a decisiones gubernamentales - provenientes sobre todo del Ministerio de Salud y Protección Social- y judiciales. La suspensión de la fumigación, como se ha visto antes, era una demanda básica, no solamente del campesinado cocalero, sino de muchos sectores sociales en los territorios.

Así, pues, el programa comenzó bajo los mejores auspicios. Pero del PNIS no ha resultado el 'grado mínimo de confianza' que el Estado reclamaba, por una razón sencilla: los incumplimientos relativos al PNIS empezaron también desde el primer día, y se han ido acumulando progresivamente hasta desembocar en la hostilidad activa del gobierno actual hacia el programa.

El gobierno de Santos, en efecto, no transfirió a tiempo los primeros pagos de campesinos que YA habían sustituido (las exigencias para los usuarios del programa eran severas: tenían que arrancar hasta la última mata de coca antes de poder recibir los recursos contemplados en la sustitución, así como denunciar a quienes no lo hicieran en su 'comunidad'). Como lo indican Acero et al. (2020), esto se debe a que el gobierno Santos improvisó la puesta en marcha del programa ante la evidencia de que había crecido abruptamente el número de hectáreas cultivadas con coca. Pero, además, la implementación del programa fue muy pobre. Estuvo marcada por una debilidad burocrática extraordinaria (Gutiérrez, Machuca \& Cristancho, 2020). Por otro lado, la erradicación forzada siguió sobre el tapete, incluyendo la fumigación con glifosato, lo que obligó al ya saliente vicepresidente, Óscar Naranjo, a enviar un parte de tranquilidad a las familias involucradas en el PNIS en Tumaco (Radio Online, 2018).

Aspectos cruciales del programa se estancaron en su trámite en el Congreso. Particularmente duro para los campesinos fue que la llamada 
Ley de Alternatividad Penal - que en esencia despenaliza el involucramiento en cultivos ilícitos con tal de que hubiera erradicación voluntaria en el marco del PNIS - fuera sometida a una sustancial distorsión bajo la presión de la Fiscalía y de varios actores partidistas. Con todo y eso, en el momento en que escribo estas líneas aún no se ha aprobado. Aunque en el Acuerdo Final se establecía que el PNIS estaría íntimamente ligado a la llamada Reforma Rural Integral (RRI), esto no sucedió, entre otras cosas, porque la RRI no ha arrancado.

Mientras tanto, los campesinos involucrados en el programa sufrían una exclusión creciente y sistemática. Este lenguaje no es exagerado. Por ejemplo, aunque para entrar al PNIS los campesinos tenían que firmar un contrato con el Estado, la gran mayoría nunca recibió su copia. El poder simbólico de esta omisión es enorme. Además, literalmente muchos campesinos comenzaron a ser sacados del programa por transgresiones mínimas, a veces inexistentes (para más detalles sobre los incumplimientos en el territorio, ver Gutiérrez, Cristancho \& Machuca, 2020). Junto con eso, era claro ya que muchos líderes de sustitución estaban siendo asesinados, por narcos que se oponían activamente a la sustitución, por disidencias de las FARC, por grupos herederos de los paramilitares o por redes en las que participaban todos los anteriores.

En 2018 llegó a la Presidencia Iván Duque, cuyo partido militaba abiertamente en contra del proceso de paz. Eso no lo salvó de recibir críticas públicas de parte de Trump (El Espectador, 2019) por el crecimiento de hectáreas sembradas con coca, entre otros asuntos. En todo caso, Duque ya había planteado regresar a la fumigación aérea con glifosato, y en junio de 2019 anunció que esta era "un hecho" (Semana, 2019). Después de recibir la aprobación tácita por parte de la Corte Constitucional, el gobierno se apresta para implementarla. También ha puesto en marcha todo un aparato de erradicaciones forzadas - que desde el principio convivieron mal con el PNIS, a veces dando origen a terribles tragedias; ver la masacre de Tumaco de 2017 (Verdad Abierta, 2017)-. En 2020, el director encargado del PNIS concedió una entrevista en la que descalificaba el programa, así como a los campesinos que se habían involucrado en él (El Espectador, 2020). 


\section{Explicando el incumplimiento}

La sección anterior expone que el ciclo del incumplimiento sigue un patrón característico: el Estado recibe una presión, la aplaca firmando un acta o acuerdo, y después no cumple con lo firmado. Ese patrón tiene algunos rasgos que vale la pena destacar, pues ayudan a desechar varias explicaciones fáciles. Primero, no expresa ni de lejos el poder aplastante del Estado, si mucho su astucia y su capacidad de evasión. De hecho, tanto la gran mayoría de relatos escritos con los que contamos como las entrevistas con tomadores de decisiones hacen énfasis en el desorden y la descoordinación reinantes dentro del conjunto de actores estatales, así como el pánico que les producían las movilizaciones. Eso no obsta para que el componente de violencia y coerción contra líderes sociales y actores sociales haya sido muy grande en los procesos descritos en el apartado anterior. Pero esa violencia se desarrolla típicamente en medio del desorden y de una combinación de proveedores públicos y privados de seguridad. Segundo, todos los involucrados estaban conscientes de los costos implicados en mantenerse dentro del ciclo del incumplimiento. Por ejemplo, los costos reputacionales del ciclo para el Estado no solamente son muy grandes, sino que los tomadores de decisiones lo sabían. Pensándolo bien, era muy difícil que no pudieran entenderlo. No hablemos ya de las ventanas de oportunidad que el ciclo abre a actores armados no estatales.

Una explicación fácil del ciclo es que los sucesivos programas de sustitución/erradicación hayan fracasado por incumplimiento de los campesinos. De hecho, algunas de las voces reseñadas en Bermúdez (2018) parecían creer que el PNIS podría contener "incentivos perversos" que empujarían a los campesinos a resembrar. Pero era un razonamiento puramente deductivo, no basado en evidencia. Aunque aún carecemos de análisis sistemáticos que comparen la respuesta desde abajo a los diversos programas de sustitución, todo lo que sabemos apunta en la dirección contraria. Jaramillo et al. (1989) reportan que los involucrados en el Proyecto Caguán se atuvieron a sus compromisos. Un documento interno del Plante dice lo mismo sobre los miembros de su propio programa (DAPRE, 1996a). Lo mismo ha sucedido con el PNIS: la UNODC reporta que el $95 \%$ de los compromisos de sustitución fueron cumplidos por 
los campesinos (UNODC \& PNIS, 2019). Solo he encontrado una posible mención al incumplimiento por parte de los campesinos reportada en Ríos (1997), ${ }^{6}$ pero allí se refiere más bien al hecho de que los campesinos organizaron otro paro en 1996. El único peligro actual -por desgracia, creciente- de resiembra proviene de una suerte de profecía autocumplida, debido a la no implementación del PNIS.

La diferencia entre los niveles de cumplimiento de las dos partes involucradas tiene muchas explicaciones posibles. En una economía como la cocalera poderse atener a la palabra empeñada es muy importante. Más aún, los sistemas de incentivos de ambas partes están marcados por una asimetría brutal. Distintos gobiernos y programas han introducido fuertes mecanismos para desincentivar la reincidencia, por ejemplo, combinando erradicación forzada con sustitución voluntaria -como lo dice bastante explícitamente un importante documento interno del Plante, que en este particular es especialmente claro; los parámetros del PNIS no son muy diferentes ${ }^{7}$ (DAPRE, 1996b)-. Y, como muestro en 2020, a pesar de la prosperidad relativa generada por la coca, los campesinos tienen en realidad muy buenas razones para tratar de hacer el tránsito hacia una economía legal. De hecho, hay buena evidencia de que al entrar en el PNIS tuvieron la disposición de sacrificar una parte no insignificante de sus ingresos ya limitados para hacer ese tránsito.

Lo que está por explicar, entonces, es el incumplimiento sistemático por parte de sucesivos gobiernos, con sus respectivos programas (todos bajo el marbete, a propósito, de desarrollo alternativo). Propongo ahora la explicación de tal incumplimiento desde la perspectiva de los problemas de la red de coaliciones que soporta la política contra los cultivos ilícitos.

La primera observación clave aquí es que la política antidrogas colombiana hace parte de una guerra global, relacionada íntimamente en la práctica pero también en la doctrina con la guerra contrainsurgente. Por consiguiente, requiere de coordinación y apoyos en todos los niveles

6 Obviamente, aquí no estoy contando el brusco incremento de hectáreas sembradas en coca antes del comienzo del programa, que, según algunos periodistas y analistas, se debió a una promoción consciente de las FARC en trance de desmovilización para que la gente pudiera acceder al PNIS. Pero en ese momento no existía ningún acuerdo formal.

7 Sabemos por declaración del equipo de apoyo técnico del gobierno en el proceso de paz que esa fue una de sus preocupaciones primordiales (Bermúdez, 2018). 
territoriales, desde Estados Unidos hasta el ámbito de lo local, donde finalmente se operacionaliza la política, así como de la coordinación de una multiplicidad de actores y agencias, cuyo papel en ambas guerras es y ha sido crucial. Consideremos esquemáticamente cómo han funcionado en este contexto los problemas de alineación de coaliciones a distintos niveles territoriales.

Estados Unidos ha presionado a los gobiernos colombianos para la implementación de medidas draconianas contra los cultivos ilícitos: por un lado, siente desconfianza hacia el sistema político colombiano -algo que estuvo presente desde la década de 1970 y dio origen a mecanismos como la certificación (Matthiesen, 2001; Pardo, 2020)_; por el otro, responde a demandas de su propio electorado, que contiene importantes nichos cada vez más extremos en materias relacionadas con la moral pública (así como a empresarios políticos dedicados a promover el tema). Eso ha llevado no solo a una radicalización de la posición del Estado colombiano en estas materias, sino a una creciente injerencia de Estados Unidos en la toma de decisiones en estos asuntos. En la práctica, la política contra los cultivos ilícitos en Colombia es binacional, de manera más o menos abierta. El caso extremo es el del gobierno de Ernesto Samper, quien por haber ganado la Presidencia con dineros del Cartel de Cali percibía que no podía darse el lujo de tolerar ambigüedad alguna en este terreno. Obviamente, muchos tomadores de decisiones y actores nacionales colombianos sentían que tenían mucho que ganar con la promoción precisamente de este tipo de políticas. También agencias con gran peso en la toma de decisiones nacionales, como el Ejército, podían estar predispuestas a favor de una política dura contra los cultivos ilícitos por al menos tres razones. Primero, el vínculo explícito entre guerra contrainsurgente y guerra contra las drogas, que se formalizó en toda una serie de documentos y decisiones de política. Segundo, y por ello mismo, la identificación del "campesinado ilícito" (Ramírez, 1996) como blanco fácil en el desarrollo de operaciones antisubversivas. Tercero, sistemas de incentivos provenientes de la interacción entre Colombia y Estados Unidos, que ofrecen a burocracias armadas y civiles involucradas en la guerra contra las drogas dinero, aparato y formación del personal.

Sin embargo, en términos del crucial vínculo entre nación y región, esas políticas draconianas no pudieron construir una coalición territorial 
estable que las soportara. Hay tres razones para que ello haya sido así. Primero, los costos humanos y ecológicos de las fumigaciones simplemente son demasiado altos; actores que dependen del voto y/o de la aprobación social en sus regiones no se pueden dar el lujo de apoyar las fumigaciones. Segundo, no se puede ignorar que la economía cocalera ha generado externalidades positivas -es decir, impactos favorablesen sus territorios. Por consiguiente, políticas como las fumigaciones necesariamente despertaron en ellos una gran animadversión. Tercero, en los municipios pequeños alcaldes y concejales tenían que responder más directamente a sus ciudadanos, y ellos mismos podían sufrir en carne propia los efectos nefastos de las fumigaciones. No hablemos ya de distintas formas de sociabilidad de base -incluidas las juntas de acción comunal, creadas por el Estado en 1958-, que se sintieron terriblemente agredidas con las fumigaciones. Además, en regiones como el Amazonas, los gobiernos no podían ignorar la existencia de una red transnacional -profundamente enraizada en regiones y localidades- por la defensa del medio ambiente.

Por esa clase de fracturas territoriales, programas como el Plante se quejaban de que "la opinión ambiental - pública y privada- confrontó abiertamente la fumigación aérea de los cultivos ilícitos y estigmatizó al Plante por promover la ganadería bovina en las zonas de colonización de la Amazonia" (DAPRE, 1996b). Como apunté en la sección anterior, esto se expresó también en fracturas dentro del Estado.

Cuarto, contrariamente a lo que se podría pensar, incluso con incentivos como 'la promoción de la ganadería', el Estado central no siempre pudo alinear alrededor de sus políticas anticultivos a sus grandes apoyos y al núcleo central de sus coaliciones territoriales en la guerra antisubversiva: las élites agrarias, los notables regionales y los políticos clientelistas. Por el contrario, como enuncié antes, en algunas coyunturas críticas estos poderes regionales e intermediarios claves se opusieron a las fumigaciones. Como vimos en la sección anterior, políticos muy paramilitarizados en su momento -como Miguel Pinedo Vidal $-{ }^{8}$ reaccionaron enérgicamente contra las fumigaciones. Entender por qué no es tan difícil. Ellos tenían una relación que era en esencia de dependencia

8 Ambos fueron condenados y pasaron por la cárcel. 
mutua con los paramilitares, a su vez grandes proveedores de seguridad al mundo territorial de cultivadores de marihuana y coca (como Hernán Giraldo). También estaban íntimamente relacionados con economías legales asociadas a la guerra que querían proteger a estos paramilitares narcotizados. Por ejemplo, Trino Luna representaba a grandes intereses agrarios, pero también tenía íntimos vínculos con el paramilitarismo. El banano y la gran ganadería, dos economías orgánicamente vinculadas a este en la región, jugaban así mismo un papel protagónico en el mundo gremial del Magdalena.

La respuesta paramilitarizada del Estado colombiano al desafío insurgente, en efecto, añadió una dimensión de complejidad a las políticas contra los cultivos. Los paramilitares eran aliados del Estado en la guerra contrainsurgente, pero estaban vinculados a diferentes eslabones de la cadena del narcotráfico, incluyendo en algunos casos los cultivos ilícitos, a través de distintas formas de control territorial (Gutiérrez, 2019). La toma paramilitar de algunas regiones - como el Catatumbo (CNMH, 2018) - se llevó a cabo en íntima alianza con burocracias armadas y civiles del Estado, pero a la vez tenía como objetivo explícito por parte de los paramilitares apoderarse de los cultivos hasta el momento controlados por diversas guerrillas. Pero esta forma de expansión era bastante incompatible con los objetivos y las políticas que las élites estatales estaban acordando con Estados Unidos.

Por supuesto, también nos encontramos en estas dificultades para alinear a actores claves alrededor de coaliciones estables de apoyo a las políticas del gobierno central un efecto de lucha clientelar pura y dura. Los programas de sustitución -casi siempre de origen nacional y armados a toda velocidad por un puñado de tecnócratas en la capital- podían entrar rápidamente en contradicción con las expectativas y dinámicas políticas en el territorio. En un importante documento de autoevaluación, funcionarios del Plante concluían amargamente que la "formulación y construcción" del programa

fue vista como un esfuerzo de los especialistas sin virtualmente ninguna participación de los actores regionales y locales ni de los destinatarios, los gobernadores y alcaldes. Intuyeron en el Plante una fuente fresca de recursos para sus propios programas de gobierno pero sin 
incurrir en compromisos de lucha frontal contra los cultivos ilícitos. Los políticos regionales y locales y los representantes a concejos, asambleas y juntas de acción comunal se convirtieron en enemigos oficiosos del Plante y, retroalimentando su propia desinformación, equipararon el plan con programas interdictivos de fumigación aérea (DAPRE, 1996b).

Esta conclusión, llena de una autocompasión y un pathos poco comunes en documentos técnicos gubernamentales, revela, no obstante, qué tanta animadversión generó la fumigación en el mundo de la política regional que se suponía constituía el nicho más favorable posible al gobierno de Samper.

Detengámonos un instante en estas tensiones. Una veta analítica fundacional - proveniente de Tilly y otros-supone que las autoridades locales promueven las políticas más conservadoras y punitivas contra la población. Otra plantea que la descentralización es esencialmente democratizadora $\mathrm{y}$, por lo tanto, destaca los componentes represivos provenientes del Estado central y las capacidades de resistencia de los actores territoriales tomados en su conjunto. Lo que estamos observando aquí es algo un poco distinto: la creación de coaliciones diferenciales alrededor de las dos grandes guerras y sus correspondientes políticas (a menudo inconsistentes entre sí), que van siendo apropiadas al tenor de la interacción entre el sistema de incentivos ofrecido por cada política y la composición de fuerzas sociales en el mundo de lo local. Por ejemplo, las élites rurales de la Sierra Nevada en efecto estaban promoviendo las soluciones más brutales en el terreno contrainsurgente, pero precisamente por su relación con paramilitares altamente articulados a las economías ilícitas se opusieron a las fumigaciones masivas en su territorio. En el sur del país, las iniciativas pro fumigación por parte del Estado central también se encontraron con una oposición más o menos activa de un sector significativo de las élites políticas, pero por razones distintas. En esas regiones no había ni hay economías de la magnitud de las que se encuentran en Santa Marta, pero, en cambio, distintos sectores políticos con acceso a los gobiernos departamental y municipal juegan un papel clave no solamente en la vida pública en el territorio, sino en la intermediación entre este y el Estado central. Las fumigaciones masivas son eventos con tal potencial de destrucción y de desestabilización de 
vidas que pocos políticos pueden darse el lujo de apoyarlas. Adicionalmente, y como he mencionado antes, la provisión de bienes públicos en el territorio ha estado en el centro de las demandas de las sucesivas oleadas de movilizaciones cocaleras, lo que daba incentivos fuertes a actores también dentro de las élites regionales y los distintos sectores de intermediarios para participar en actividades contra la fumigación, $\mathrm{y}$, por consiguiente, para desalinearse de las coaliciones que se estaban promoviendo desde Bogotá y Washington.

Sin embargo, debe notarse que el intento de construir una coalición sólida a favor de la sustitución voluntaria de cultivos también enfrentó grandes dificultades. Es verdad que distintas élites que al principio estaban apostándole a la guerra descubrieron en algún momento que valía la pena tratar de sacarle réditos a la paz en sus respectivas regiones - por ejemplo, en la apuesta de Santos de vincular la pacificación regional con la expansión de la frontera agrícola (Gutiérrez, 2019b)-. Pero la paz dividió brutalmente la política regional. Por un lado, dada la naturaleza de esa política, los intermediarios que estaban fuera del gobierno tenían incentivos muy fuertes para atacar a la paz (eso fue lo que sucedió con el Partido Liberal oficialista y el Pacto del Caguán de la década de 1980, según se describió anteriormente). Por el otro, algunas agencias nacionales claves operaron en contra de cualquier proyecto de sustitución, lo que a su vez llevó a otras -y a actores dentro de distintos niveles territoriales- a adoptar una actitud expectante.

Todo eso se reflejó en una enorme descoordinación entre agencias y en una increíble incapacidad del Estado de construir una semblanza de aparato burocrático para responder a las demandas desde el territorio. Ella ya está bastante bien documentada (Jaramillo, et al., 1989; Ramírez, 2001; Acero, et al., 2020): programas débiles, cuya financiación depende de entes más consolidados, con poquísimo personal, casi siempre funcionando en una suerte de interinidad y a término fijo -ver también la evaluación interna del Plante sobre este particular (DAPRE, 1995c)-. Igualmente, queda en evidencia la incapacidad de construir coaliciones viables a todos los niveles territoriales importantes. Como el centro de toma de decisiones acerca de la política antidrogas no ha estado en Colombia - sino más bien se ha negociado y decidido entre Washington y Bogotá-, el gobierno ha operado con una lógica de minimización 
de costos, tratando de evitar reacciones extremas tanto por parte de agentes en los territorios productores como por parte de agentes globales. El asunto, por supuesto, se ha ido complicando a medida que más actores - también a todos los niveles territoriales- encuentran que las políticas antidrogas tienen efectos relevantes sobre su agenda (piénsese en aquellos relacionados con la defensa del medio ambiente).

Los acuerdos con los movimientos cocaleros han sido esfuerzos por controlar esas reacciones. Pero estos acuerdos solo eran viables si pasaban por el proceso político - en el Congreso, por ejemplo-. En esa clase de trámites, cualquier persona que estuviera promoviendo el cumplimiento de los acuerdos podía ser señalada de complicidad con actores ilegales, y enfrentar a actores abrumadoramente poderosos (como el Ejército colombiano o Estados Unidos). Pocos políticos prácticos quieren quedar en esta situación. La nube de intermediarios entre nación y región que podía tener incentivos para oponerse coyunturalmente a las fumigaciones no estaba particularmente interesada en promover una presencia más burocrática y universalista del Estado colombiano en las regiones, entre otras cosas, porque eso minaría su propio poder. Más aún, la dotación de bienes públicos tendría que ser sufragada con impuestos, algo a lo que importantes élites agrarias se han opuesto de manera tajante. Solamente así se puede entender el contraste entre la enorme importancia que tanto el Estado colombiano como sus aliados internacionales atribuyen al problema de los cultivos ilícitos y la pobre financiación de los respectivos programas. Por ejemplo, el Plante funcionó en esencia con dineros de otras políticas públicas a los que simplemente les pusieron otro marbete, y con plata de la cooperación internacional. No hablemos ya del Proyecto Caguán, que en términos de magnitud fue bastante marginal. En contraste, las fumigaciones -bastante más costosas - han estado muy bien financiadas, con recursos estadounidenses, y han contado con el apoyo y el aparato logístico del Ejército.

En algunas coyunturas decisivas, encontramos que la debilidad burocrática es precisamente expresión directa de la dificultad extrema para alinear a todos los actores claves a diferentes niveles territoriales. Por ejemplo, el PNIS se comenzó antes de lo esperado, sin personal y sin planeación, para poder calmar la ansiedad estadounidense ante el aumento de hectáreas cultivadas de coca (Acero, et al., 2020). Todo 
el trámite, en buena parte fallido, del PNIS revela cuán difícil fue ese alineamiento: los apoyos del gobierno Santos en el Congreso eran curtidos operadores regionales, la mayoría de ellos provenientes del uribismo; algunos de los más importantes estaban involucrados en procesos de despojo de tierras (Gutiérrez, 2019b). Es difícil imaginarlos promoviendo una transformación regional basada en el acceso de los campesinos a la tierra. Por lo que se dijo antes, es perfectamente entendible, en cambio, que hayan por lo menos aceptado no oponerse a la suspensión provisional de las fumigaciones.

En síntesis: las políticas draconianas contra los cultivos ilícitos fueron en buena medida resultado de una imposición o al menos de un proceso de toma de decisión extranacional (binacional). No obstante, algunos actores globales no la apoyaban claramente. A nivel nacional, diversas agencias estatales y partidos las respaldaron con entusiasmo y lograron construir desde allí apoyos significativos. En el nivel departamental, políticos y élites económicas significativas -intermediarios claves en la relación nación-región- sintieron sus costos, y en coyunturas críticas se opusieron a ellas. También lo hicieron actores territoriales con gran peso político y moral, como la Iglesia. Lo mismo se puede decir de muchos gobernadores. Liderazgos y habitantes de los municipios - sobre quienes recaía ya de manera muy directa el costo de tales políticas- estuvieron radicalmente en contra. A la vez, los actores de las economías ilegales no podían estar de acuerdo con ellas. Esa es la estructura de oportunidad que genera grandes movilizaciones campesinas. Ante ellas, los gobiernos, con las coaliciones territoriales de apoyo rotas, entran en pánico y tratan de negociar a toda velocidad. Pero después los acuerdos a los que llegan gobierno y campesinos pasan por la criba del trámite político, del control judicial y de la aprobación estadounidense, y las conquistas básicas se caen. Esto lleva a incumplimientos masivos. Lo que crea las condiciones para que se inicie un nuevo ciclo.

Nótese el contraste con las políticas contrainsurgentes. Allí también el Estado colombiano se enfrentó a serios problemas de acción colectiva, debido a la respuesta paramilitarizada al desafío guerrillero (Gutiérrez, 2019). Aunque la guerra contra el comunismo también nació y contó con el patrocinio estadounidense, la posición de la constelación de fuerzas claves alrededor de aquellas políticas fue muy distinta. Generalmente 
las demandas más salvajes y acerbas de represión vinieron desde los intermediarios regionales y los territorios, mientras que diferentes actores en Estados Unidos jugaron ocasionalmente un papel protector (piénsese en los debates alrededor de los derechos humanos en la década de 1990, que fueron institucionalizados alrededor de aun otro proceso de certificación). Como he descrito aquí, a menudo los mismos intermediarios que estaban exigiendo políticas de protección en uno $\mathrm{u}$ otro sentido estaban involucrados en dinámicas homicidas -lo que mostré en la sección anterior no es tan excepcional (ver Ciro, 2014)-. Miguel Pinedo provee una diciente ilustración a estas dos historias contrapuestas: intermediario poderoso entre región y nación, representante de economías legales e ilegales claves, promotor impenitente del paramilitarismo, pero difícil por eso mismo de alinear en las coaliciones relacionadas con economías ilícitas. Otro buen ejemplo lo provee Trino Luna Morón -el padre del famoso 'parapolítico', terrateniente y cercano a diversos intereses empresariales-.

\section{Conclusiones}

¿Por qué el Estado colombiano responde a las demandas del mundo cocalero a través de 'ciclos de incumplimiento' - es decir, reacciona ante la protesta con acuerdos que después incumple-? Vimos al principio del artículo que, por separado, cada una de las razones para que ni el Estado ni sus tomadores de decisiones quisieran involucrarse en el ciclo de incumplimiento es muy importante; en conjunto, tienen un peso muy grande. Sin embargo, no han generado las condiciones para salir de las lógicas del ciclo a lo largo de los años. ¿Por qué no solo tolera, sino que genera repetidamente ciclos de incumplimiento? He intentado plantear aquí una primera respuesta a tal pregunta.

Sugerí aquí que el ciclo no se podía atribuir solamente a las tendencias excluyentes o represivas del Estado colombiano. Esas proclividades están obviamente presentes a lo largo de toda la narrativa, a veces en sus formas más crudas y salvajes. Pero no dan cuenta de la esencia del ciclo, porque hay que explicar sus dos momentos (adquirir unos compromisos para luego ignorarlos) y no solamente uno de ellos. Por 
el contrario, propuse que la explicación del ciclo podría provenir de la dificultad del Estado colombiano para alinear a los actores claves en coaliciones estables a todos los niveles territoriales alrededor de alguna opción de política relativa a los cultivos ilícitos.

Adoptar esta perspectiva permite no solamente evadir algunos de los problemas conceptuales relacionados con las nociones de debilidad o presencia del Estado, sino además entender bien las fracturas estatales en Colombia desde la identificación y exhibición de los mecanismos que las producen. Este proceso de identificación y exhibición tiene tres ventajas. Primero, uno de sus puntos focales es el vínculo entre las condiciones políticas que permiten una forma organizacional y la manera en que esta se desenvuelve - algo que debería confluir con el "materialismo organizacional" del propio Mann (1993)-. Las políticas públicas no tienen lugar en un vacío de poder. Todos los Estados, pero sobre todo los formados sobre el dominio indirecto, necesitan construir coaliciones a diferentes niveles territoriales para que sus políticas sean aprobadas, transmitidas e implementadas. Más aún tratándose de políticas como la paz o la sustitución/erradicación en Colombia, que carecen inicialmente de siquiera una semblanza de burocracia universalista que pueda desarrollarlas en todo el territorio (esto las acerca más al tipo ideal dominio indirecto por medio de intermediarios y redes clientelistas). En caso de que alinear esas coaliciones resulte difícil o imposible, la probabilidad de que se presenten catástrofes burocráticas se hace más alta -aunque obviamente también esto ocurre sobre un trasfondo de dificultades de coordinación, ineptitud administrativa e incuria que tienen su dinámica propia-. Dicho de otra manera, la perspectiva desde las coaliciones adoptada aquí permite identificar la debilidad político-administrativa, pero a la vez mirarla desde el proceso político.

Segundo, permite entender al Estado como 'una cosa' - un conjunto de organizaciones jerarquizadas (Skocpol, 2015) cuyas directivas "emanan del centro" (Mann, 1993) - y a la vez como una relación. En particular, destaca los problemas de acción colectiva dentro del Estado. Estos problemas acompañan la implementación de políticas relativamente benévolas, a veces también constructivas, pero también aquellas homicidas (capturas paramilitares del territorio, etc.). Como señalé en la revisión de literatura, una de las líneas de ataque a la noción de debilidad 
o fragilidad estatal consiste en decir que la debilidad es más bien una maniobra astuta que permite generar los desenlaces que en todo caso querían las élites. Esta idea debe considerarse un retroceso, en la medida en que toma al Estado o a las élites como un bloque homogéneo. Los mecanismos a través de los cuales los Estados construyen las condiciones de posibilidad para desarrollar políticas vitales para ellos parecen ser un punto de partida más interesante. Para avanzar en esta dirección, el concepto de la capacidad de alinear actores para construir coaliciones parecería ser vital.

Tercero, todo esto revela una vez más (Gutiérrez, 2014, 2019) que no hay un 'locus del mal' territorial cuando se trata de identificar la fuente de los errores y horrores del Estado colombiano. No se trata, en particular, de que el mundo de lo local o regional sea más brutal o 'incivilizado' que el centro estatal residente en Bogotá. Vemos de hecho que muchas de las desgracias narradas en este artículo provienen a menudo no solo de la capital, sino de mucho más lejos. El énfasis que he puesto aquí es en el tipo de interacción, que casa bien con los conceptos que he usado para desarrollar la argumentación. Conceptos como el del dominio indirecto, por ejemplo, son típicamente relacionales. Ahora bien, las interacciones varían de acuerdo con los aspectos sustantivos de la política: están histórica y territorialmente ancladas. Así, por ejemplo, las coaliciones y los alineamientos de las políticas antidrogas y los de las políticas contrainsurgentes, con todo y su vinculación explícita -que encuentra múltiples expresiones políticas, burocráticas y coercitivas-, fueron diferentes. También divergieron los problemas de acción colectiva que los marcaron. Destacaría que este corolario a la narrativa es importante: las posiciones de las distintas élites en sus diferentes niveles territoriales, así como las valoraciones que se hagan de ellas, dependen de la política y el problema concreto a la mano, y no pueden establecerse deductivamente de antemano. Esto lleva al análisis a un terreno no contemplado por los estudios clásicos de Tilly y otros teóricos belicistas, en quienes encontramos una tensión entre Estado central y poderes regionales más o menos homogénea a lo largo de todo el espectro de las políticas.

Termino considerando cuatro objeciones a lo que he presentado aquí. Primero, como dije en la introducción, los incumplimientos no 
marcan únicamente la relación del Estado central con territorios y movilizaciones cocaleros. Ya mencioné que las movilizaciones alrededor de otras economías, como la petrolera, también tienen una larga tradición de incumplimientos; más aún, muchos colombianos en general sienten que el incumplimiento es una marca de la política y del Estado colombianos. ¿No debilita eso el argumento? Creo que no, en la medida en que, aunque el incumplimiento en general puede marcar la relación del Estado colombiano con distintos sectores sociales, la dificultad de procesar institucionalmente demandas sociales que está en su base es particularmente aguda en relación con respecto de los cultivos de uso ilícito y los territorios que los albergan. Incluso en un mismo territorio el tratamiento de las demandas sociales provenientes de los cultivos ilícitos parece particularmente difícil por las razones obvias. El ciclo petrolero putumayense generó indignación y asonadas, pero no fue tan costoso y masivo como el cocalero (entre otras cosas porque este último estaba relacionado con una economía ilegal). Así, la explicación a partir de coaliciones ofrece un argumento general -la modalidad de gobierno indirecto a la colombiana dificulta la implementación de muchas políticas públicas en la medida en que estas requieren la alineación de actores e intermediarios claves- y a la vez muestra cómo el caso particular lo expresa de manera concentrada.

Segundo, y en la dirección contraria, podría aducirse que no todos los acuerdos con los campesinos cocaleros se incumplen. Una vez más: ¿no contradice eso la proposición básica que he presentado aquí? Los cumplimientos parciales a movimientos regionales cocaleros no deben extrañar mucho, precisamente porque estos se han dirigido no solamente contra la exclusión, sino también contra el abandono. Muchos de los pliegos de los campesinos contienen un amplio espectro de demandas relativas a la provisión de bienes públicos. Esta provisión a menudo estaba ya prevista y presupuestada por otras políticas públicas antes de la movilización, aunque había sido retenida por distintas razones (entre otras, intervención de intermediarios interesados en darles otros destinos al dinero, etc.). La presión desde abajo ayudó a solucionar esta clase de bloqueos. Pero otros temas, como voluntariedad y gradualidad en la sustitución, tratamiento diferencial, no fumigación o no represión, constituyen la pepa dura del incumplimiento: allí las cosas no han mejorado, y 
en algunos casos de hecho se han deteriorado. En efecto, la gradualidad en la sustitución era aceptable en la década de 1980, pero ya no (tampoco en el marco del PNIS). Ahora bien, algunas movilizaciones parecen realmente haber tenido éxito en sacar adelante demandas claves para el territorio (naturalmente, aquí cualquier avance es parcial). Un ejemplo posible podría ser el paro del Catatumbo de 2013. Mi conjetura es que, de validarse esto eventos, pueden explicarse precisamente por los alineamientos que los permitieron. Por eso es que mi proposición debe estar planteada en términos probabilísticos: dados los desalineamientos entre actores claves a distintos niveles territoriales, la probabilidad de que el Estado cumpla sus compromisos y tramite institucionalmente las demandas acordadas con los movimientos y territorios relacionados con cultivos ilícitos es baja.

Tercero: no me he referido aquí a las guerrillas ni a otros actores ilegales que hubieran podido contribuir a las movilizaciones contra las fumigaciones. Ramírez (2001) resalta que en 1996 las FARC contribuyeron tanto con financiación como con presión para que los campesinos se movilizaran, una aserción que corroboran múltiples fuentes, aunque, por supuesto, eso ha cambiado de región a región y de año a año. Pero el marco conceptual y el foco de preocupación de este artículo ha sido la toma de decisiones dentro del Estado. Aunque la guerra contrainsurgente atraviesa todo el análisis, me concentro en mirar la respuesta estatal y, por lo tanto, las coaliciones intrasistémicas. Nótese, no obstante, que la participación de todos los actores ilegales está cubierta por el argumento coalicional: son poderosos a distintos niveles territoriales, y a través de su alineamiento o no con distintas políticas a veces pueden facilitar o, por el contrario, a veces tratar de bloquear su implementación.

Cuarto: no he destacado el papel de los partidos. En efecto, este es crucial, como se nota ya en el trabajo de Jaramillo et al. (1989). Como las diferentes políticas sobre los cultivos ilícitos han estado articuladas a diferentes procesos de paz, las fracturas correspondientes han sido más agudas y estridentes. Esto se nota con claridad en la actual coyuntura, con el incumplimiento del PNIS íntimamente relacionado con -aunque no enteramente dependiente de - el triunfo de una coalición política antipaz. Aquí he planteado el problema de las coaliciones desde la perspectiva de la toma de decisiones en diversos niveles territoriales; 
un análisis de los arreglos y redes partidistas y su relación tanto con las políticas contrainsurgentes como con las relacionadas con las economías ilícitas necesariamente haría parte de una agenda de investigación sobre coaliciones.

\section{Referencias}

\section{Académica}

Bermúdez Liévano, A. (2018). Los debates de La Habana: una mirada desde adentro. Bogotá: IFIT.

Blok, A. (1974). The mafia of a Sicilian village, 1860-1960. A study of violent peasant entrepreneurs. Illinois: Waveland Press.

Castaneda, E., \& Schneider, C. L. (Eds.). (2017). Collective violence, contentious politics and social change. A Charles Tilly reader. New York-London: Routledge.

Centro Nacional de Memoria Histórica (CNMH). (2018). Catatumbo: memorias de vida y dignidad. Bogotá: CNMH.

Ciro, A. (2014). Poderes políticos locales, violencia y configuración del Estado: el caso de Fernando Almario en el Caquetá. Análisis Político, (82), 58-71.

Díaz Uribe, E., Tulande, F., \& Riveros, N. (Eds.). (2018). Sustitución de cultivos: camino lícito hacia la paz. Bogotá: Brújula Comunicación Estratégica.

García, M., E Espinosa, R. (2014). El derecho al Estado. Los efectos legales del apartheid institucional en Colombia. Bogotá: Dejusticia.

González González, F. E. (2014). Poder y violencia en Colombia. Bogotá: Cinep.

Gutiérrez Sanín, F. (2014). El orangután con sacoleva. Cien años de democracia y represión en Colombia. Bogotá: Random House.

Gutiérrez Sanín, F. (2019). Clientelistic warfare: paramilitaries and the State in Colombia. Oxford: Peter Lang.

Gutiérrez Sanín, F. (2019b). The politics of peace: competing agendas in the Colombian agrarian agreement and implementation. Peacebuilding, 7(3), 314-328. https://doi.org/10.1080/21647259.2019.1621247

Gutiérrez Sanín, F., Machuca Pérez, D., \& Cristancho, S. (2019). ¿Obsolescencia programada? La implementación de la sustitución y sus inconsistencias. Análisis Político, 32(97), 136-160. https://doi.org/10.15446/anpol.v32n97.87197

Jaramillo, J. E., Mora, L., \& Cubides, F. (1989). Colonización, coca y guerrilla. Bogotá: Alianza Editorial Colombiana. 
Karl, R. A. (2017). Forgotten peace: reform, violence, and the making of contemporary Colombia (violence in Latin American history). University of California Press. Mann, M. (1993). The sources of social power. Volumes 1 and 2. Cambridge University Press.

Ocampo, G. (2015). Poderes regionales, clientelismo y Estado: etnografías del poder y la política en Córdoba, Colombia. Bogotá: Cinep-Programa por la Paz-Odecofi-Colciencias.

Ramírez, M. C. (2001). Entre el Estado y la guerrilla: identidad y ciudadanía en el movimiento de los campesinos cocaleros del Putumayo. Bogotá: Instituto Colombiano de Antropología e Historia.

Ramírez, M. C. (2005). Construction and contestation of criminal identities: the case of the "cocaleros" in the Colombian Western Amazon. Journal of Drug Issues, 35(1), 57-82.

Ramírez, W. (1996). ¿Un campesinado ilícito? Análisis Político, (29), 54-62.

Romero, M. (2003). Paramilitares y autodefensas 1982-2003. Bogotá: IEPRI.

Skocpol, T. (2015). States and social revolutions. Cambridge: Cambridge University Press.

Torres, M. C. (2011). Estado y coca en la frontera colombiana. El caso de Putumayo. Bogotá: Odecofi-Cinep.

UNODC, E PNIS. (2019). Monitoreo a la implementación del Plan de Atención Inmediata - componente familiar. Recuperado de https://www.unodc.org/documents/ colombia/2020/Febrero/INFORME _ EJECUTIVO _ PNIS_No._19.pdf

\section{Archivo}

Acta de Acuerdos entre la Mesa Regional de Organizaciones Sociales del Putumayo, Alta Bota Caucana y Jardines de Sucumbíos de Ipiales y el Gobierno Nacional. (2014).

Archivo General de la Nación (AGN). (1974). Carta a Roberto Arenas, ministro de Gobierno, 8 de enero.

DAPRE. (1995a). Carta de la Iglesia al Presidente para evitar fumigaciones en Putumayo. Vicariato Apostólico de Sibundoy.

DAPRE. (1995b). Quinto informe de avance al Presidente. Héctor Moreno Reyes, $1^{\circ}$ de noviembre.

DAPRE. (1995c). Acuerdo Marco para la Cooperación entre el Gobierno de Colombia y el UNDCP para la Implementación del Plan Nacional de Desarrollo Alternativo "Plante". 
DAPRE. (1996a). Monitoreo y seguimiento a la utilización del crédito Plante. Luis Eduardo Parra Rodríguez.

DAPRE. (1996b). Retrospectiva del Plante. Fernando Franco.

\section{Prensa}

(31 de enero de 1992). Pinedo Vidal se opone al glifosato. El Informador.

(21 de octubre de 1993). Organizaciones civiles se oponen a fumigación aérea con glifosato. El Informador.

(15 de diciembre de 1994). Comisión del gobierno al Guaviare. El Tiempo. Recuperado de https://www.eltiempo.com/archivo/documento/MAM-266092

(12 de enero de 1995). Terminó el paro en Putumayo. El Tiempo. Recuperado de https://www.eltiempo.com/archivo/documento/MAM-305653

(31 de julio de 1996a). Paros, arma campesina. El Espectador.

(30 de julio de 1996b). La Hormiga agitadora. El Espectador.

(30 de octubre de 1996). La aguda crisis económica creará un paro administrativo. La Nación.

(6 de octubre de 2017). Tumaco, atrapado entre sustitución y erradicación de cultivos ilícitos. Verdad Abierta. Recuperado de https://verdadabierta. com/tumaco-atrapado-entre-sustitucion-y-erradicacion-de-cultivos-ilicitos/ (junio de 2018). “Uso del glifosato en Tumaco no afectará el programa de sustitución para 18000 familias": Vicepresidente. Radio Online. Recuperado de http://islenramirez.com/uso-del-glifosato-en-tumaco-no-afectara-elprograma-de-sustitucion-para-18-000-familias-vicepresidente/

(2 de febrero de 2019). ¿Por qué los estudiantes saldrán nuevamente a las calles el 10 de octubre? Semana. Recuperado de https://www.semana. com/educacion/articulo/por-que-los-estudiantes-saldran-protestaran-el10-de-octubre/634377

(10 de abril de 2019). Trump critica a Duque y acusa a Colombia de enviar criminales y droga a EE. UU. El Espectador. Recuperado de https://www. elespectador.com/noticias/el-mundo/trump-critica-duque-y-acusa-colombiade-enviar-criminales-y-droga-eeuu-articulo-849812

(18 de junio de 2019). Gobierno listo para fumigación aérea, ¿qué dirá la Corte? Semana. Recuperado de https://www.semana.com/nacion/articulo/ gobierno-listo-para-fumigacion-aerea-que-dira-la-corte/620127

(24 de enero de 2020). "Líderes de sustitución de cultivos no han sido asesinados": director del programa de sustitución. El Espectador. 
Recuperado de https://www.elespectador.com/colombia2020/pais/ lideres-de-sustitucion-de-cultivos-no-han-sido-asesinados-director-delprograma-de-sustitucion-articulo-901193?_twitter_impression=true

Profesores Departamento de Antropología. (4 de abril de 2019). La minga ha puesto en el debate los incumplimientos a los pueblos indígenas. Universidad de los Andes. Recuperado de https://uniandes.edu.co/es/noticias/antropologia/ la-minga-ha-puesto-en-el-debate-nacional-los-incumplimientos-a-los-pueblosindigenas

Quilindo, C. (2 de mayo de 2019). Minga indígena denuncia primeros incumplimientos del gobierno nacional. RCN Radio. Recuperado de https:// www.rcnradio.com/colombia/sur/minga-indigena-denuncia-primerosincumplimientos-del-gobierno-nacional 